\title{
Somatotypological Characteristics of Adult Women with Type 2 Diabetes in Yakutia
}

\author{
Vilyuia A. Alekseeva, PhD*; Alla B. Guryeva, PhD; Natalia V. Borisova, PhD, ScD; \\ Lubov A. Sydykova, PhD; Palmira G. Petrova, PhD, ScD; Alena A. Osinskaya, PhD \\ M. K. Ammosov North-Eastern Federal University \\ Yakutsk, the Republic of Sakha (Yakutia), Russia
}

\begin{abstract}
The aim of the study was to present somatotypological characteristics of women (age 36-74 years) of Yakut ethnicity with type 2 diabetes (T2D).

Materials and Methods: The examined women with diagnosed T2D belonged to the age group of 36-55 years $(\mathrm{n}=24)$ and the group of 56-74 years $(n=64)$. The comparison group $(n=826)$ consisted of women of the same age periods who were not suffering from T2D. All examined women were born and permanently resided in Yakutia. Anthropometric examination, bioelectrical impedance analysis and the somatotypological method of examination were performed.

Results: The results indicate a significant predominance of overweight and obesity in Yakut women with T2D. Somatotypological analysis by the Rees-Eysenck body index, the Tanner scale and the Heath-Carter method also revealed a number of features. In the group of women with T2D, we found that individuals with andromorphic body type (according to sexual dimorphism index) and mesoectomorphic body type (according to the Heath-Carter index) were prevalent and that the proportion of individuals with asthenic somatotype, according to the Rees-Eysenck body index, was smaller. Identification of marked body types in the female population of Yakutia can serve as an additional prognostic criterion in a complex of studies aimed at the early detection of T2D.(International Journal of Biomedicine. 2019;9(4):320-323.)
\end{abstract}

Key Words: type 2 diabetes $\bullet$ women $\bullet$ somatotype $\bullet$ Yakutia

\section{Abbreviations}

AO, abdominal obesity; BIA, bioelectrical impedance analysis; BShI, body shape index; BMI, body mass index; BW, body weight; BH, body height; BI, the Brugsch index; ChC, chest circumference; HC, hip circumference; HCI, the Heath-Carter index; ISD, sexual dimorphism index; IRPW, the index of the relative pelvic width; REBI, the Rees-Eysenck body index; T2D, type 2 diabetes; $\mathbf{W C}$, waist circumference.

\section{Introduction}

In the past three decades, the prevalence of type 2 diabetes (T2D) has risen dramatically in countries of all income levels. T2D comprises the majority of people with diabetes around the world, and is largely the result of excess body weight and physical inactivity. ${ }^{(1)}$

Corresponding author: Vilyuia A. Alekseeva, PhD. M. K. Ammosov North-Eastern Federal University, Yakutsk, the Republic of Sakha (Yakutia),Russia. E-mail: viljen1974@mail.ru
The average prevalence of T2D in Russia as of January 1, 2019, was 2,885.7/100 thousand of the population. ${ }^{(2)}$ In Yakutia, there is a significant and constant increase in the number of people with T2D. By 2016, according to the Federal Register of Diabetes, the number of patients with T2D had risen to 20,508 people. ${ }^{(3)}$

Healthy diet, regular physical activity, maintaining a normal body weight and avoiding tobacco use are ways to prevent or delay the onset of T2D. Early diagnosis of diabetes can delay the occurrence of formidable complications, thereby prolonging the patient's working capacity and active 
life. Along with the known methods for the early diagnosis of T2D, such as BIA and anthropometric examination, there is also the somatotypological method, which is non-invasive and relatively non-laborious. It is known that the reactivity of the body, temperament characteristics, and endocrine and immunological status of a person are all related to the somatotype..$^{(4,5)}$ In this regard, somatotypological diagnosis is a promising method for a personalized approach to the prevention and early diagnosis of $\mathrm{T} 2 \mathrm{D}$.

The aim of the study was to present somatotypological characteristics of women (age 36-74 years) of Yakut ethnicity with T2D.

\section{Materials and Methods}

We examined 88 women who were hospitalized in the endocrinology department of the Center for Emergency Medicine in the period from January to March 2019 with diagnosed T2D. The examined women belonged to the age group of 36-55 years $(n=24)$ and the group of 56-74 years $(n=64)$. The comparison group $(n=826)$ consisted of women of the same age periods who were not suffering from T2D. All examined women were born and permanently resided in Yakutia. Anthropometric examination, BIA and the somatotypological method of examination were performed. Exclusion criteria were the presence of an implanted pacemaker and pregnancy.

Anthropometric examination was carried out according to standard methods. ${ }^{(6)} \mathrm{BH}$ was measured using a Tanita digital anthropometer with an accuracy of $0.1 \mathrm{~cm}$. BW was measured without clothing using medical scales with an accuracy of $50 \mathrm{~g}$.

The girths of hip, chest and waist were determined using centimetric tape. The diameters of shoulders $(\mathrm{ShD})$, intercristal diameter (ID) of the pelvis, and transverse and anteroposterior diameters of the chest were measured with a large caliber compass with an accuracy of $1 \mathrm{~mm}$.

BMI was calculated using Quetelet's formula (in $\mathrm{kg} / \mathrm{cm}^{2}$ ). WC was measured using centimetric tape at the navel level on a horizontal line (in $\mathrm{cm}$ ). BMI between $18.5 \mathrm{~kg} / \mathrm{m}^{2}$ and $25 \mathrm{~kg} /$ $\mathrm{m}^{2}$ indicated a normal weight. $\mathrm{BMI}<18.5 \mathrm{~kg} / \mathrm{m}^{2}$ was considered underweight. BMI between $25 \mathrm{~kg} / \mathrm{m}^{2}$ and $29.9 \mathrm{~kg} / \mathrm{m}^{2}$ was considered overweight. BMI $\geq 30 \mathrm{~kg} / \mathrm{m}^{2}$ indicated obesity. ${ }^{(7)}$ The $\mathrm{WC} / \mathrm{HC}$ ratio of $\geq 0.8$ was considered elevated. ${ }^{(8)}$ All women examined were identified by somatometric indices. ${ }^{(9)}$

IRPW was calculated by the formula: $\mathrm{IRPW}=\mathrm{ID}(\mathrm{cm}) \times 100 / \mathrm{BH}(\mathrm{cm})$

The values of IRPW $<16.0$ characterized the narrow pelvis; IRPW 16.0-17.9 the intermediate pelvis; and IRPW $\geq 18.0$ the wide pelvis.

The body shape was determined by BShI:

$\mathrm{BShI}=\mathrm{ID}(\mathrm{cm}) \times 100 / \mathrm{ShD}(\mathrm{cm})$

The values of BShI $<70.0$ characterized the trapezoid shape; BShI 70-74.9 the intermediate shape; and BShI $\geq 75.0$ the rectangle shape.

The relative width of the chest was determined using BI: $\mathrm{BI}=\mathrm{ChC}(\mathrm{cm}) \times 100 / \mathrm{BH}(\mathrm{cm})$

The values of $\mathrm{BI}<50.0$ characterized the narrow chest; $\mathrm{BI}$ 50.0-55.0 the medium-wide chest; and $\mathrm{BI}>55.0$ the wide chest.
Somatotypes were diagnosed using the following methods: the Rees-Eysenck body index (REBI), the Tanner scale and the Heath-Carter method.

The somatotype according to $\mathrm{REBI}^{(10)}$ was determined by the formula:

$$
\mathrm{REBI}=\mathrm{BH} \times 100 /(\mathrm{ChC} \times 6)
$$

The values of REBI $<96.0$ characterized the picnic somatotype; REBI 96-106 the normosthenic somatotype; and REBI $>106.0$ the asthenic somatotype.

The body type was determined in accordance with the Tanner scale (sexual dimorphism index, ISD), ${ }^{(11)}$ calculated by the formula:

$$
\mathrm{ISD}=3 \times \mathrm{xBAD}-\mathrm{ID},
$$

where BAD - bisacromial diameter (shoulder width), $\mathrm{cm}$. The values of ISD $<73.1$ characterized the gynomorphic body type; ISD 73.1-82.1 the mesomorphic body type; and ISD $>82.1$ the andromorphic body type.

The body type, according to HCI, was assessed based on BIA using the ABC-01 MEDASS device. ${ }^{(12)}$ To measure total body impedance, a pair ofelectrodes is placed at the extremity of the upper limbs and another pair at the extremity ofthe lower limbs. ${ }^{(13,14)}$ The examination protocols automatically calculated scores of endomorphy, mesomorphy and ectomorphy. According to $\mathrm{HCI}$, there are 13 somatotypes, which are determined by a combination of ecto-, meso-, and endomorphy scores.

The study was approved by our regional ethics committee. Written informed consent was obtained from all patients before inclusion in the study.

Statistical analysis was performed using statistical software package SPSS version 17.0 (SPSS Inc, Chicago, IL). Variables were presented as median (Me) and interquartile ranges (IQR; 25th to 75th percentiles). Mann-Whitney U test was used to compare means of 2 groups of variables not normally distributed. The frequencies of categorical variables were compared using Pearson $\chi^{2}$ or Fisher's exact test, when appropriate. A probability value of $P<0.05$ was considered statistically significant.

\section{Results and Discussion}

According to study data, average $\mathrm{BH}$ and $\mathrm{BW}$ were $157.5[153.0 ; 161.7] \mathrm{cm}$ and $75.0[70.0 ; 88.3] \mathrm{kg}$, respectively. BMI was equal to $31.45[27.1 ; 33.6] \mathrm{kg} / \mathrm{m}^{2}$. A BMI deficiency was not found among the women examined. Normal BMI was determined in $8(9.1 \%)$ women, overweight in $28(31.8 \%)$, and obesity in 52(59.1\%) women. WC and HC were 95.5 [89.0; $103.7] \mathrm{cm}$ and $103.5[95.0 ; 109.5] \mathrm{cm}$, respectively. AO (WC $\geq 88 \mathrm{~cm}$ ) was detected in $78(88.6 \%)$ women. The $\mathrm{WC} / \mathrm{HC}$ ratio was 0.94 [0.86; 0.99]: within the normal range in $8(9.1 \%)$ women and increased in 80(90.9\%) women.

Somatotyping with REBI in patients found the asthenic somatotype in $11.4 \%$ of cases, the normosthenic somatotype in $50.0 \%$, and the picnic somatotype in $38.6 \%$ of cases. In the comparison group, we found the asthenic samotype in $31.4 \%$ of cases, the normosthenic samotype in $41.0 \%$, and the picnic samotype in $27.6 \%$ of cases. 
We found the gynomorphic body type, according to ISD, in $47.7 \%$ of patients, the mesomorphic body type in $43.2 \%$, and the andromorphic body type in $9.1 \%$. The distribution of somatotypes in the comparison group was as follows: the gynomorphic type $-33.2 \%$, mesomorphic type $-64.9 \%$, the andromorphic type $-1.9 \%$.

According to $\mathrm{HCI}, 93.2 \%$ of patients had a mesoectomorphic body type. A balanced ectomorphic type was detected in $2.3 \%$ of cases, an endoectomorphic type in $4.5 \%$. The scores of endomorphy, ectomorphy and mesomorphy are presented in Table 1 . In the comparison group, somatotyping with HCI was not performed.

Table 1.

The scores of endomorphy, ectomorphy and mesomorphy in T2D women according to $\mathrm{HCI}$

\begin{tabular}{|l|c|c|c|}
\hline \multicolumn{1}{|c|}{ Somatotype } & $\begin{array}{c}\text { Scores of } \\
\text { endomorphy }\end{array}$ & $\begin{array}{c}\text { Scores of } \\
\text { ectomorphy }\end{array}$ & $\begin{array}{c}\text { Scores of } \\
\text { mesomorphy }\end{array}$ \\
\hline $\begin{array}{l}\text { Mesoectomorphic } \\
\text { type (n=82) }\end{array}$ & $\begin{array}{c}2.54 \\
{[1.95 ; 3.05]}\end{array}$ & $\begin{array}{c}6.54 \\
{[6.32 ; 6.93]}\end{array}$ & $\begin{array}{c}5.11 \\
{[4.86 ; 5.41]}\end{array}$ \\
\hline $\begin{array}{l}\text { Balanced } \\
\text { ectomorphic type } \\
\text { (n=2) }\end{array}$ & 5.63 & 6.89 & 5.79 \\
\hline $\begin{array}{l}\text { Endoectomorphic } \\
\text { type (n=4) }\end{array}$ & 5.16 & 7.39 & 3.51 \\
\hline
\end{tabular}

The intermediate and wide pelvis, according to IRPW, was found in $10.2 \%$ and $89.8 \%$ of patients, respectively. The relative width of the chest, according to BI, was - as follows: the medium-wide chest in $6.8 \%$ of patients and the wide chest in $93.2 \%$. Intermediate body shape, according to BshI, was found in $2.3 \%$ of patients and the rectangle shape in $97.7 \%$.

In the age structure of the examined women with $\mathrm{T} 2 \mathrm{D}$, the age group of 56-74 years was predominant. $\mathrm{BH}$ in the examined T2D women did not significantly differ from the general population indicators of Yakut women. BW and BMI in T2D women were significantly higher than in women without diabetes. A. Guryeva et al. ${ }^{(15)}$ found that the average BW of Yakut women in the age group of 36-55 years was $62.3[55.0 ; 70.0] \mathrm{kg}$ and in the age group of $56-74$ years $61.2[55.2 ; 70.5] \mathrm{kg}$. BMI was 24.87 [22.23; 27.64] kg/m² and $26.62[22.93 ; 29.43] \mathrm{kg} / \mathrm{m}^{2}$, respectively. In accordance with BMI, in the examined group of T2D women, none were underweight. Most women (59.1\%) were obese and 31.8\% of them were overweight. In the comparison group, obesity was detected significantly less frequently $(15.3 \%$ in the age group of 36-55 years and $20.1 \%$ in the age group of 56-74 years), and normal BW was recorded more often (in $48.6 \%$ and $39.8 \%$, respectively).

It was found that WC in T2D women was significantly higher than in women without T2D $(95.5 \mathrm{~cm}$ versus $88.0 \mathrm{~cm})$. The $\mathrm{WC} / \mathrm{HC}$ ratio was also higher in $\mathrm{T} 2 \mathrm{D}$ women compared to comparison group (0.94 versus 0.89 ).

Analysis of the somatotypological characteristics of T2D women, according to REBI, revealed a predominance of individuals with the normosthenic somatotype $(50.0 \%)$.
Among women with T2D, the asthenic somatotype was much less common, compared with the comparison group $\left(\chi^{2}=9.556, P<0.01\right)$. A comparative analysis of the distribution of body types according to the Tanner scale showed a statistically significant predominance of the andromorphic body type among T2D women $(9.1 \%$ versus $1.9 \%)\left(\chi^{2}=14.304\right.$, $P<0.001)$. Elderly women with the normosthenic and picnic somatotypes, according to REBI, and andromorphic body type, according to the Tanner scale, can be assigned to the risk group for the development of T2D. In the group of T2D women, only 3 somatotypes were revealed, according to HCI: mesoectomorphic, balanced ectomorphic, and endoectomorphic types. There was a significant predominance of individuals with a mesoectomorphic body type (93.2\%).

According to IRPW, BI and BShI, we can conclude that most of the T2D women had a wide pelvis, a wide chest, and a rectangular body shape.

Numerous studies in the field of clinical anthropology indicate the predisposition of representatives of different somatotypes to the occurrence of certain pathologies. ${ }^{(16)}$ For the development of T2D, the results show a lesser predisposition of individuals with an asthenic body type. In women, the andromorphic body type is an extreme somatotype, which can be considered a risk factor for the development of T2D. Thus, the results indicate a significant predominance of overweight and obesity in Yakut women with T2D. Somatotypological analysis by the Rees-Eysenck body index, the Tanner scale and the Heath-Carter method also revealed a number of features. In the group of women with T2D, we found that individuals with andromorphic body type (according to ISD) and mesoectomorphic body type (according to $\mathrm{HCI}$ ) were prevalent and that the proportion of individuals with asthenic somatotype, according to REBI, was smaller. Identification of marked body types in the female population of Yakutia can serve as an additional prognostic criterion in a complex of studies aimed at the early detection of T2D.

\section{Competing Interests} interests.

The authors declare that they have no competing

\section{References}

1. WHO. Diabetes. Fact sheet. 30 October 2018. Available from: https://www.who.int/news-room/fact-sheets/detail/ diabetes

2. Dedov II, Shestakova MV, Vikulova OK. [Epidemiology of diabetes mellitus in Russian Federation: clinical and statistical report according to the federal diabetes registry]. Diabetes mellitus. 2017;20(1):13-41. doi: 10.14341/DM8664. [Article in Russian].

3. Afanasyev KE, Borisova EA. [Economic losses from diabetes: the true extent of the problem in modern conditions]. Trends in the development of science and education. 2017;25(3):28-30. [Article in Russian].

4. Nikityuk DB. [The level of functional reserves of the human body and morpho-psycho-functional relationships]. Russian Journal of Rehabilitation Medicine. 2017;4: 3-14. [Article in Russian]. 
5. Koinosov PG, Thiryateva TV, Orlov SA, Koinosov AP, Putina NY, Stogniy OM, et al. [Prospects for the development of clinical anthropology]. Meditsinskaya nauka i obrazovanie Urala. 2015;16(1):153156. [Article in Russian].

6. Bunak VV. Anthropometry: a practical course. M.: State Educational and pedagogical Publishing House of the Ministry of Education of the RSFSR;1941. [In Russian].

7. Maternal anthropometry for prediction of pregnancy outcomes: memorandum from a USAID/WHO/PAHO/Mother Care meeting. Bull. Word Health Organ. 1991; 69(5): 523-532.

8. Romanova AN, Voevoda MI. Metabolic syndrome and coronary atherosclerosis in residents of Yakutia: ethnic and gender characteristics. Novosibirsk: Nauka; 2016. [In Russian].

9. Khrisanfova EN, Perevozchikova IW. Anthropology. Moscow: Naula; 2005. [In Russian].

10. Rees WL, Eisenck H. A factorial study of some morphological aspects of human constitution. J. Mental Sci. 1945;91:219-232.

11. Tanner JM. The growth and constitution of man. Human biology: Transl. From English. Moscow; 1968:247-326.
12. Rudnev SG, Soboleva, NP, Sterlikov SA, Nikolaev DV, Starunova OA, Chernykh SP, et al. Bioimpedance study of body composition in the Russian population. M.: RIO TSNIIOIZ, 2014. [In Russian].

13. Kolesnikov VA, Rudnev SG, Nikolaev DV, Anisimova AV, Godina EZ. [On a new protocol of the Heath-Carter somatotype assessment using software for body composition bioimpedance analyzer]. Moscow University Anthropology Bulletin (Vestnik Moskovskogo Universiteta. Seria XXIII. Antropologia). 2016; 4: 4-13. [Article in Russian].

14. Nikolaev DV, Rudnev SG. [Bioimpedance analysis: basis of method, record of inquiry and interpretation of measurements]. Sports medicine: research and practice. 2012;2:29-36. [Article in Russian].

15. Gureva AB, Nikolaev VG, Alekseeva VA. [Ethno-age features of the physical status of the female population of the Republic of Sakha (Yakutia)]. Modern problems of science and education. 2018;4:181. [Article in Russian].

16. Nikolaev VG, Medvedev NN, Nikolenko VN, Petrova MM, Sindeeva LV, Nikolaev NN, and others. Essays on integrative anthropology: a monograph. Krasnoyarsk: Krasnoyarsk State Medical University; 2015. [In Russian]. 